\title{
Pathophysiological Concentrations of Glucose Promote Oxidative Modification of Low Density Lipoprotein by a Superoxide-dependent Pathway
}

\author{
Mitsunobu Kawamura, ${ }^{\star}$ Jay W. Heinecke, ${ }^{\ddagger}$ and Alan Chait * \\ ${ }^{*}$ Department of Medicine, University of Washington, Seattle, Washington 98195; and ${ }^{\ddagger}$ Department of Medicine, Washington University, \\ St. Louis, Missouri 63110
}

\begin{abstract}
Oxidized lipoproteins may be important in the pathogenesis of atherosclerosis. Because diabetic subjects are particularly prone to vascular disease, and glucose autoxidation and protein glycation generate reactive oxygen species, we explored the role of glucose in lipoprotein oxidation. Glucose enhanced low density lipoprotein (LDL) oxidation at concentrations seen in the diabetic state. Conjugated dienes, thiobarbituric acid reactive substances, electrophoretic mobility, and degradation by macrophages were increased when LDL was modified in the presence of glucose. In contrast, free lysine groups and fibroblast degradation were reduced. Although loss of reactive lysine groups could be due to either oxidative modification or nonenzymatic glycation of apolipoprotein B-100, inhibition of lipid peroxidation by the metal chelator, diethylenetriamine pentaacetic acid, blocked the changes in free lysines. Thus, glycation of lysine residues is unlikely to account for the alterations in macrophage and fibroblast uptake of LDL modified in the presence of glucose. Glucose-mediated enhancement of LDL oxidation was partially blocked by superoxide dismutase and nearly completely inhibited by butylated hydroxytoluene. These findings indicate that glucose enhances LDL lipid peroxidation by an oxidative pathway involving superoxide and raise the possibility that the chronic hyperglycemia of diabetes accelerates lipoprotein oxidation, thereby promoting diabetic vascular disease. (J. Clin. Invest. 1994. 94:771-778.) Key words: peroxidation - superoxide - hydrogen peroxide • macrophages $\cdot$ diabetes
\end{abstract}

\section{Introduction}

Atherosclerosis is a leading cause of morbidity and mortality in patients suffering from diabetes mellitus. Although other disorders associated with vascular-disease, such as hypertension, central obesity, and hyperlipidemia, frequently coexist with the diabetic state (1), they appear inadequate to explain the increased risk of atherosclerosis. These observations suggest that additional factors may be involved in the accelerated macrovascular disease of diabetes.

Address correspondence to Dr. Alan Chait, Department of Medicine, Division of Metabolism, Endocrinology and Nutrition RG-26, University of Washington, Seattle WA 98195. 1994.

Received for publication 16 June 1992 and in revised form 11 May

J. Clin. Invest.

(C) The American Society for Clinical Investigation, Inc.

0021-9738/94/08/0771/08 \$2.00

Volume 94, August 1994, 771-778
Epidemiological, clinical, and genetic investigations indicate that elevated levels of low density lipoprotein (LDL) are another important risk factor for coronary artery disease. Although LDL levels are frequently normal in diabetic patients, hyperlgycemic or other metabolic alterations secondary to the diabetic state may alter lipoproteins to a form that promotes atherogenesis. One such modification may be the nonenzymatic glycation of LDL which has been shown in some (2), but not all, studies ( 3 ) to be taken up rapidly by macrophages in culture. The unregulated uptake of modified lipoproteins by macrophages is likely to play a pivotal role in cholesterol accumulation, a key early event in lesion formation. Autoantibodies against glycated LDL (4) also might result in the formation of immune complexes, which have been postulated to stimulate macrophage foam cell formation (5). Recently, there has been considerable interest in oxidized LDL, another modification of lipoproteins that may play an important role in atherogenesis $(6,7)$. LDL can be oxidatively damaged in vitro by endothelial cells, monocyte-macrophages, and arterial smooth muscle cells (for review see reference 7). Lipoxygenases may be involved in the oxidative modification of LDL by endothelial cells and macrophages $(7,8)$, whereas superoxide plays an important role in LDL oxidation by arterial smooth muscle cells and activated monocytes $(9,10)$. Oxidized LDL is thought to promote atherogenesis by a multitude of different mechanisms $(7,11)$.

Indirect evidence suggests that lipoprotein oxidation may be increased in diabetes. First, increased levels of thiobarbituric acid reactive substances (TBARS) ${ }^{1}$ have been demonstrated in plasma from diabetic subjects (12). Although TBARS increase during oxidative modification of lipoproteins, their presence in plasma is not specific for products of lipid peroxidation. Second, plasma lipoproteins isolated from diabetic rats have increased TBARS and are cytotoxic to cultured cells (13), which suggests that they may have been oxidatively modified in vivo. Both lipoprotein TBARS content and cytotoxicity were reduced either by antioxidants or by treatment of hyperglycemia with insulin (13). Finally, glucose autoxidation $(14,15)$ and nonenzymatic protein glycation $(15,16)$ can result in the generation of oxygen-free radicals, such as superoxide, which stimulate lipoprotein oxidation $(9,10)$. Indeed, a recent study has suggested that LDL lipid peroxidation is enhanced by high concentrations of glucose (17).

In the current studies we have explored the relationships between elevated levels of glucose, the hallmark of the diabetic state, and the oxidative modification of LDL. We show that glucose promotes lipoprotein oxidation by a pathway that involves superoxide. Human monocyte-derived macrophages rap-

1. Abbreviations used in this paper: BHT, butylated hydroxytoluene; DTPA, diethylenetriamine pentaacetic acid; TBARS, thiobarbituric acid reactive substances; TNBS, trinitrobenzenesulfonic acid. 
a Conj. Dienes

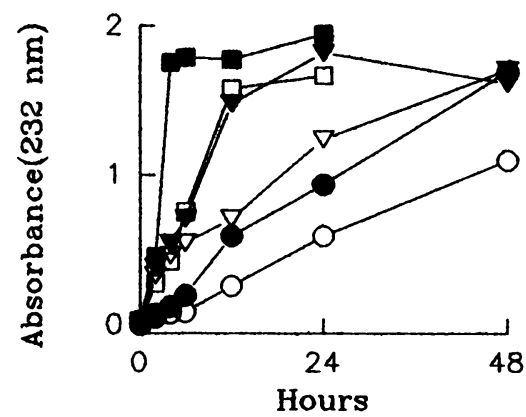

c TBARS

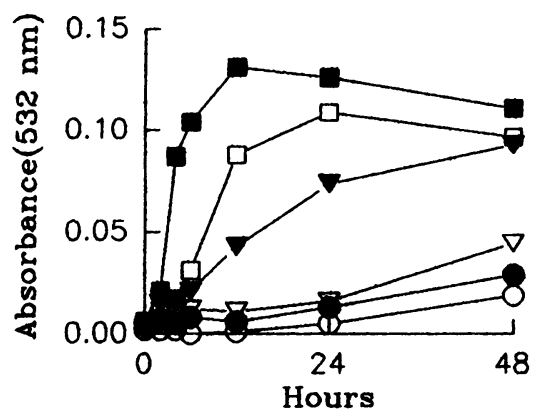

b Lipid Peroxides

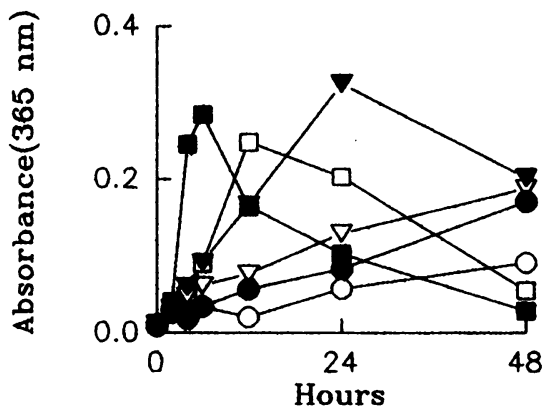

d LDL Electrophoretic Mobility

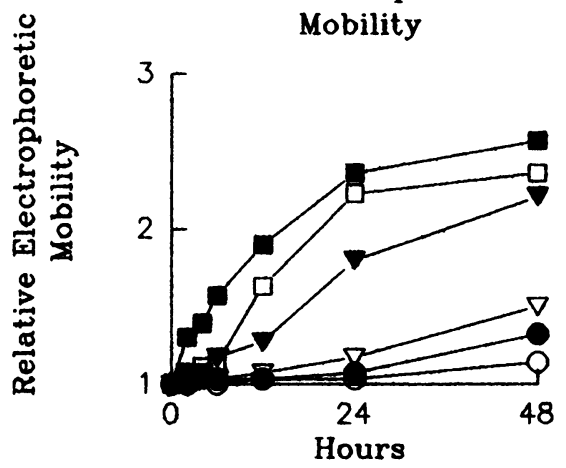

Figure 1. Time course of glucose-mediated LDL oxidation. LDL ( $200 \mu \mathrm{g} / \mathrm{ml})$ was incubated in sodium phosphate buffer $(100 \mathrm{mM}$, $\mathrm{pH} 7.4)$ and $1 \mu \mathrm{M}$ EDTA with: no additions $(\bigcirc), 25 \mathrm{mM}$ glucose $(\bullet), 0.5 \mu \mathrm{M} \mathrm{CuSO}_{4}(\nabla)$, $25 \mathrm{mM}$ glucose and $0.5 \mu \mathrm{M} \mathrm{CuSO}_{4}(\nabla), 2 \mu \mathrm{M}$ $\mathrm{CuSO}_{4}(\square)$, or $25 \mathrm{mM}$ glucose and $2 \mu \mathrm{M}$ $\mathrm{CuSO}_{4}(\square)$. The changes in conjugated dienes (Fig. $1 a$ ), lipid peroxides (Fig. $1 b$ ), TBARS (Fig. $1 c$ ), and relative LDL electrophoretic mobility (Fig. $1 d$ ) were measured as described in detail in Methods after incubation at $37^{\circ} \mathrm{C}$ under $5 \% \mathrm{CO}_{2} / 95 \%$ air for the times indicated. Values shown are means of duplicate determinations. The results shown are representative of five similar experiments. idly take up and degrade LDL modified in the presence of glucose, suggesting a potential mechanism whereby hyperglycemia favors foam cell formation and atherogenesis.

\section{Methods}

Materials. ${ }^{125} \mathrm{I}-\mathrm{Na}$ was obtained from DuPont/New England Nuclear (Boston, MA). Ficoll-paque was purchased from Pharmacia Fine Chemicals (Piscataway, NJ). Butylated hydroxytoluene (BHT), diethylenetriamine pentaacetic acid (DTPA), SOD, catalase, and glucose were obtained from Sigma Chemical Company (St. Louis, MO). Trinitrobenzenesulfonic acid (TNBS) was obtained from Pierce Chemical Company (Rockford, IL). DMEM and RPMI 1640 culture medium, fetal calf serum, penicillin-streptomycin, and L-glutamine were from GIBCO BRL (Gaithersburg, MD).

Lipoproteins. LDL was prepared from human plasma (EDTA 4 $\mathrm{mM}$ ) that was treated immediately after separation from red cells with $1 \mu \mathrm{M}$ (final concentration) phenylmethysulphonyl fluoride. The density of the plasma was increased to $1.30 \mathrm{~g} / \mathrm{ml}$ by the addition of solid $\mathrm{KBr}$, and LDL $(d=1.019-1.063 \mathrm{~g} / \mathrm{ml})$ was isolated by discontinuous density gradient ultracentrifugation in a vertical rotor (VTi-50; Beckman Instruments, Inc., Fullerton, CA) by the method of Chung et al. (18). All solutions used for lipoprotein preparation contained 1 mM EDTA. After one wash at $d=1.063 \mathrm{~g} / \mathrm{ml}$, the isolated LDL was extensively dialyzed under $\mathrm{N}_{2}$ at $4^{\circ} \mathrm{C}$ against $150 \mathrm{mM} \mathrm{NaCl}$ and $1 \mathrm{mM}$ EDTA ( $\mathrm{pH} 7.4$ ) over $24 \mathrm{~h}$, stored at $4^{\circ} \mathrm{C}$ under $\mathrm{N}_{2}$ in the dark, and used within 2 wk.

$L D L$ modification. After the removal of the EDTA by dialysis against phosphate-buffered solution under $\mathrm{N}_{2}$ at $4^{\circ} \mathrm{C}$, LDL ( $200 \mu \mathrm{g}$ of protein $/ \mathrm{ml}$ ) was incubated with the indicated additions in $100 \mathrm{mM}$ sodium phosphate buffer ( $\mathrm{pH} 7.4$ ) containing $1 \mu \mathrm{M}$ EDTA at $37^{\circ} \mathrm{C}$ under $5 \% \mathrm{CO}_{2} / 95 \%$ air. Oxidation was arrested by refrigeration and by the addition of $50 \mu \mathrm{M}$ DTPA and $25 \mu \mathrm{M}$ BHT (9). The extent of LDL lipid peroxidation was evaluated using diene conjugation, iodide reactive material, and by the appearance of TBARS (19). Conjugated dienes were assessed by monitoring the increase in absorbance at $232 \mathrm{~nm}$ as described by Esterbauer et al. (20) using $160 \mu \mathrm{g}$ of LDL protein in a final volume of $0.8 \mathrm{ml}$. Lipid peroxides were measured directly by means of the iodometric assay described by El-Saadani et al. (21) using $40 \mu \mathrm{g}$ of LDL protein in a final volume of $1 \mathrm{ml}$. TBARS were measured as described by Buege and Aust (22) using $40 \mu \mathrm{g}$ of LDL protein in a final volume of $1.5 \mathrm{ml}$. Preliminary experiments indicated that neither glucose (at concentrations of up to $25 \mathrm{mM}$ ) nor copper (at micromolar concentrations) interfered with the assays (data not shown). The coefficients of variation for the conjugate diene, lipid peroxidase, and TBARS assays were $2.6,4.2$, and $10.9 \%$, respectively. LDL was acetylated as described by Basu et al. (23) and radiolabeled by the iodine monochloride method as modified for lipoproteins by Bilheimer et al. (24) using ${ }^{125} \mathrm{I}-\mathrm{Na}$.

Cells. Human monocyte-derived macrophages were isolated by density gradient centrifugation by the method of Böyum (25). The mononuclear cell band was washed twice at $4^{\circ} \mathrm{C}$ in RPMI 1640 medium and then plated at $3 \times 10^{5}$ cells $/ 16-\mathrm{mm}$ well at $37^{\circ} \mathrm{C}$ in $5 \% \mathrm{CO}_{2} / 95 \%$ air in the same medium containing $20 \%$ ( $\mathrm{vol} / \mathrm{vol}$ ) autologous serum, 100 $\mathrm{U} / \mathrm{ml}$ penicillin, $100 \mu \mathrm{g} / \mathrm{ml}$ streptomycin, and $2 \mathrm{mM}$ glutamine (26). Monocyte-derived macrophages were fed twice weekly and used within 7-10 d of plating. Human skin fibroblasts were cultured from punch biopsies from the medial thigh of normal volunteers as described previously (26). Subcultures were used between passages 4 and 12 . The cells were plated at $7 \times 10^{4}$ cells $/ 35-\mathrm{mm}$ dish at $37^{\circ} \mathrm{C}$ in $5 \% \mathrm{CO}_{2} / 95 \%$ air in DME supplemented with $10 \%$ calf serum, $100 \mathrm{U} / \mathrm{ml}$ penicillin, and $100 \mu \mathrm{g} / \mathrm{ml}$ streptomycin. After $5 \mathrm{~d}$ in culture, the medium of the cells was changed to DME supplemented with $10 \%$ lipoprotein-deficient human serum (prepared by ultracentrifugation at $d=1.25 \mathrm{~g} / \mathrm{ml}$ ) and used after $48 \mathrm{~h}$ of incubation.

Metabolism of lipoproteins by cells. Before incubation with fibroblasts and macrophages, ${ }^{125}$ I-labeled lipoproteins were dialyzed against $150 \mathrm{mM} \mathrm{NaCl}$ with $50 \mu \mathrm{M}$ DTPA ( $\mathrm{pH} \mathrm{7.4)}$ ) to remove the reaction mixture used for modification. Uptake and degradation of the ${ }^{125} \mathrm{I}$-labeled lipoprotein ( $150-250 \mathrm{cpm} / \mathrm{ng}$ protein ) were assessed after a 5-h incubation with cells at $37^{\circ} \mathrm{C}$. LDL degradation products in the incubation medium were assayed by measurement of trichloroacetic acid-soluble 

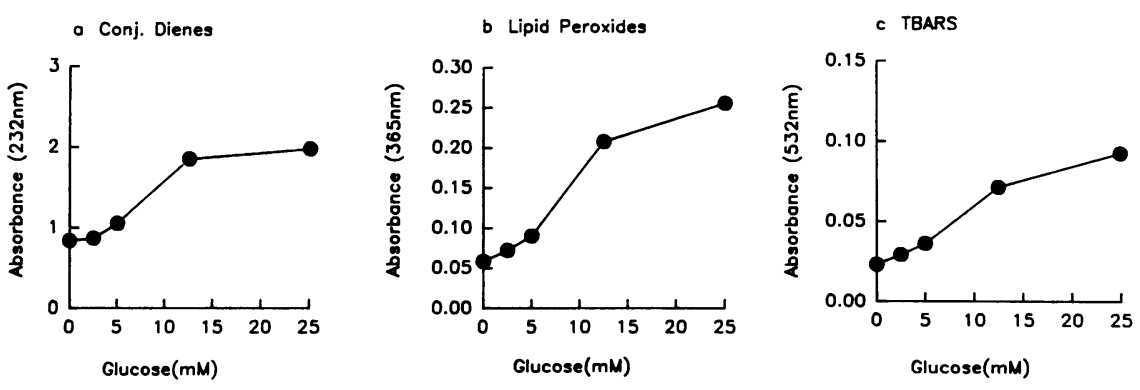

Figure 2. Glucose-stimulated LDL oxidation in the presence of copper. LDL $(200 \mu \mathrm{g} / \mathrm{ml})$ was incubated at $37^{\circ} \mathrm{C}$ for $48 \mathrm{~h}$ in $100 \mathrm{mM}$ sodium phosphate buffer, $0.5 \mu \mathrm{M} \mathrm{Cu}^{2+}$, and $1 \mu \mathrm{M}$ EDTA with the final concentration of glucose indicated, after which the medium content of conjugated dienes (Fig. $2 a$ ), lipid peroxides (Fig. 2 $b$ ), and TBARS (Fig. $2 c$ ) were determined as described in Methods. Values shown are means of duplicate determinations. The results shown are representative of three similar experiments. (noniodide) radioactivity (26). Cell-free LDL degradation, which represented $<5 \%$ of total radioactivity, was subtracted from total degradation. For measurement of protein, the cell layer was washed three times with phosphate-buffered saline at the end of the incubation and extracted by incubation at room temperature with $0.5 \mathrm{ml}$ of $0.1 \mathrm{~N} \mathrm{NaOH}$ for $1 \mathrm{~h}$.

Other assays. Protein was measured by the method of Lowry et al. (27) using bovine serum albumin as the standard. Free protein amino groups in LDL were estimated using TNBS. LDL ( $50 \mu \mathrm{g}$ of protein) was mixed with $1 \mathrm{ml}$ of $4 \% \mathrm{NaHCO}_{3}(\mathrm{pH} 8.4$ ) and $50 \mu \mathrm{l}$ of $0.1 \%$ TNBS and heated for $1 \mathrm{~h}$ at $37^{\circ} \mathrm{C}$ after which the absorbance at 340 $\mathrm{nm}$ was measured (28). LDL electrophoresis was carried out, at $\mathrm{pH} 8.6$, in barbital buffer on $0.5 \%$ agarose gel as described (26); electrophoretic mobility was expressed relative to native LDL. The specific activities of SOD and catalase were $5.4(29)$ and $58 \mathrm{U} / \mu \mathrm{g}(30)$, respectively.

\section{Results}

LDL incubated for $48 \mathrm{~h}$ in phosphate-buffered saline supplemented with $1 \mu \mathrm{M}$ EDTA underwent little modification as monitored by changes in conjugated dienes, lipid peroxides, TBARS, and electrophoretic mobility (Fig. 1). Addition of glucose to the incubation medium led to accelerated LDL oxidation in the presence of copper. All measures of lipoprotein oxidation, including conjugated dienes (Fig. $1 a$ ), lipid peroxides (Fig. 1 $b$ ), TBARS (Fig. $1 c$ ), and electrophoretic mobility (Fig. $1 d$ ), initially increased in a time-dependent fashion in the presence of $25 \mathrm{mM}$ glucose. Lipid peroxides and TBARS content reached a maximum and then fell during the 48-h incubation, whereas conjugated dienes and electrophoretic mobility increased and then remained constant. The effect of glucose on lipoprotein oxidation was concentration dependent (Fig. 2). The major increase in the oxidative modification of LDL, assessed as conjugated dienes (Fig. $2 a$ ), lipid peroxides (Fig. $2 b$ ), and TBARS (Fig. $2 \mathrm{c}$ ) was observed in the range of 5-15 $\mathrm{mM}$ of glucose. Thus, glucose markedly accelerates the oxidation of LDL in the presence of added copper.

LDL exposed to high concentrations of glucose alone in phosphate-buffered saline supplemented with $1 \mu \mathrm{M}$ EDTA for $48 \mathrm{~h}$ demonstrated a modest increase in lipid peroxidation (Fig. 1). To establish the potential role of hyperglycemia in lipid peroxidation, LDL was incubated for $72 \mathrm{~h}$ with glucose in the absence of copper. Under these conditions, 5-15 mM glucose clearly stimulated LDL oxidation, monitored as the increase in conjugated dienes, lipid peroxides, and TBARS (Fig. 3). This range of glucose concentrations is similar to that observed in diabetic patients, suggesting that LDL experiencing prolonged hyperglycemia in vivo might undergo accelerated oxidative modification.

To determine whether the glucose-induced changes in the oxidative modification of LDL were due to oxidative modifica- tion or protein glycation, experiments were performed in which lipid peroxidation was blocked by the transition metal chelator, DTPA. The extent of lipoprotein modification was determined by measurement of TBARS, which measures soluble bifunctional aldehydes derived from lipid peroxidation, and of TNBS reactivity, which measures free amine groups on protein-associated lysyl residues. In the presence of both glucose and copper, but in the absence of DTPA, TBARS progressively increased (Fig. $4 a$ ) while TNBS reactivity progressively decreased (Fig. $4 b$ ). Similar results were observed when LDL was incubated with either glucose or copper alone, or together (Fig. 4). These findings could reflect derivatization of protein amino groups by either lipid peroxidation products or by nonenzymatic glycation. When the same experiment was performed in the presence of DTPA, which inhibits lipid peroxidation, no changes were observed in either TBARS (Fig. $4 c$ ) or TNBS reactivity (Fig. 4 d). Because glycation is largely independent of transition metal ions, these results suggest that modification of apolipoprotein B100 was due to oxidation. In the absence of DTPA, the TBARS content of LDL demonstrated an inverse linear relationship with TNBS reactivity (Fig. 5), providing further evidence that protein amino groups were reacting with lipid oxidation products.

To determine the mechanism( $s$ ) by which glucose facilitates the oxidative modification of LDL, we studied the effect of several scavengers of reactive oxygen species. Stimulation of lipid peroxidation by glucose in the presence of added copper $(0.5 \mu \mathrm{M})$ was partially inhibited either by SOD $(30 \mu \mathrm{g} / \mathrm{ml})$, which catalyzes the breakdown of superoxide, or by catalase ( $50 \mu \mathrm{g} / \mathrm{ml}$ ), which catalyzes the breakdown of hydrogen peroxide (Fig. $6 d$ ). The effect of these enzymes on the inhibition of LDL oxidation was additive. Heat inactivation of either SOD or catalase eliminated their inhibitory activity (data not shown). BHT markedly inhibited glucose-mediated LDL oxidation. SOD and catalase together almost completely inhibited LDL oxidation in the presence of either glucose (Fig. $6 b$ ) or copper alone (Fig. $6 \mathrm{c}$ ). Taken together, these results indicate that the glucose- and copper-induced lipid peroxidation of LDL is likely to be dependent on a reaction pathway that requires superoxide and hydrogen peroxide.

To explore the possible role of superoxide and hydrogen peroxide in glucose-stimulated oxidation, similar studies were performed with LDL incubated for $120 \mathrm{~h}$ with $15 \mathrm{mM}$ glucose in the absence of added copper. As with glucose and copper together, SOD partially prevented LDL oxidation, measured as the increase in conjugated dienes, lipid peroxides, and TBARS ( Table I). In contrast, catalase alone had little inhibitory effect. Heat-inactivated SOD failed to block glucose-induced LDL oxidation, suggesting that enzymatic activity rather than nonspecific effects, such as metal ion binding, accounted for inhibition 
a Conj. Dienes

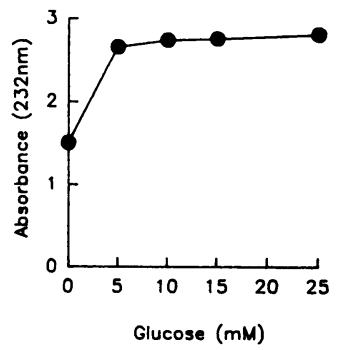

b Lipid Peroxides

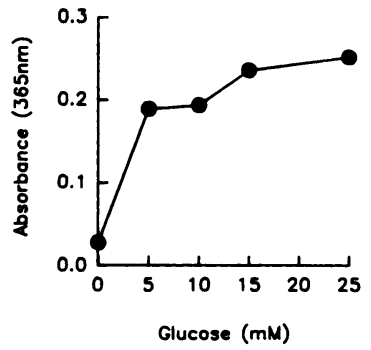

c TBARS

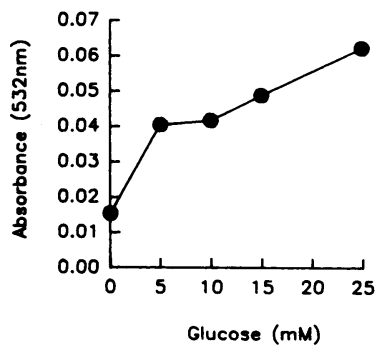

Figure 3. Glucose-stimulated LDL oxidation in the absence of copper. LDL was exposed to the indicated final concentration of glucose as described in Fig. 2 except that copper was omitted from the reaction mixture. After a 72 $h$ incubation, the medium content of conjugated dienes (Fig. $3 a$ ), lipid peroxides (Fig. $3 b$ ), and TBARS (Fig. $3 c$ ) were determined as described in Methods. Values shown are means of duplicate determinations. The results shown are representative of three similar experiments. of lipid peroxidation $(31,32)$. These results indicate that LDL oxidation by glucose, when excess copper is not added, is likely to involve superoxide but not hydrogen peroxide.

We next investigated the cellular metabolism of the modified lipoproteins using cultured human monocyte-derived macrophages and skin fibroblasts. The uptake and degradation of modified ${ }^{125} \mathrm{I}-\mathrm{LDL}$ by macrophages increased in parallel with the increase in lipid peroxidation (Fig. $7 a$ ). In contrast, the rates of degradation of these lipoproteins by fibroblasts occurred in the reverse order: LDL was degraded most rapidly, acetylated LDL was degraded least rapidly, while the oxidatively modified forms of LDL were degraded at intermediate rates (Fig. $7 b$ ). The free protein amino content of the lipoproteins showed an inverse correlation with the rate of degradation of these lipoproteins by macrophages (Fig. $8 a$ ) and a positive correlation with the rate of degradation by skin fibroblasts (Fig. $8 b$ ). Human macrophages exhibit numerous scavenger receptors but are relatively poor in LDL-receptor activity, while fibroblasts are rich in LDL receptors but lack scavenger receptor activity (33). This suggests that modification of LDL by glucose and copper results in increased recognition and uptake by the scavenger receptor and decreased recognition and uptake by the LDL receptor.

\section{Discussion}

These studies demonstrate that physiologically relevant concentrations of glucose enhance the oxidation of LDL in a cell-free system. Although the addition of glucose alone led to increased LDL oxidation, this effect was magnified in the presence of low concentrations of copper, a transition metal that is redoxactive and catalyzes lipid peroxidation $(34,35)$. The effect of glucose on LDL oxidation was most pronounced at glucose concentrations that span the range seen in the diabetic state.

To determine the mechanism( $s$ ) whereby glucose stimulated LDL lipid peroxidation, several inhibitors of reactive oxygen species were tested. LDL oxidation by glucose in the absence of added metal ions was inhibited by SOD but not by catalase. The exact mechanism for the acceleration of LDL lipid peroxidation by glucose is unknown but is likely to involve superoxide
TBARS

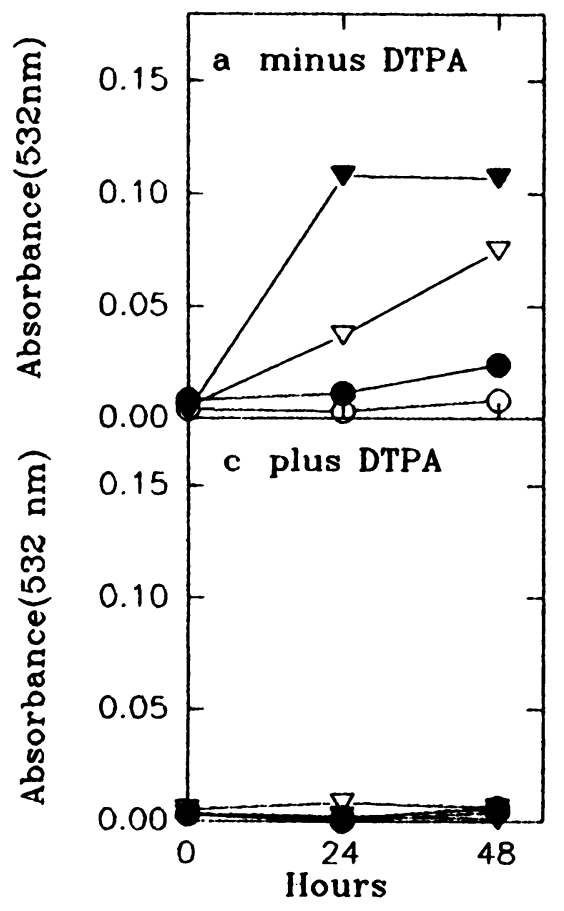

TNBS

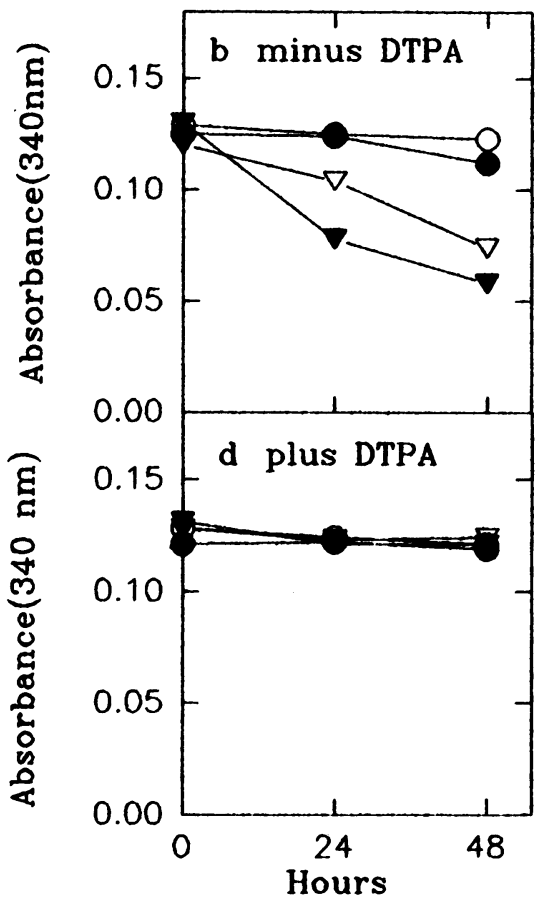

Figure 4. Lipid peroxidation and reactive lysines of modified LDL. LDL $(200 \mu \mathrm{g} / \mathrm{ml})$ was incubated with no addition ( $(0), 25 \mathrm{mM}$ glucose $(\bullet), 0.5 \mu \mathrm{M} \mathrm{CuSO}_{4}(\nabla)$, or glucose and $\mathrm{CuSO}_{4}$ simultaneously $(\nabla)$ for the indicated times, in the absence (Fig. 4, $a$ and $b$ ) or presence (Fig. 4, $c$ and $d$ ) of the metal ion chelator DTPA $(50 \mu \mathrm{M})$. Lipid peroxidation and reactive protein amino groups were monitored by measurement of TBARS and TNBS reactivity, respectively, as described in Methods. Values shown are means of duplicate determinations. The experiment was repeated twice. 


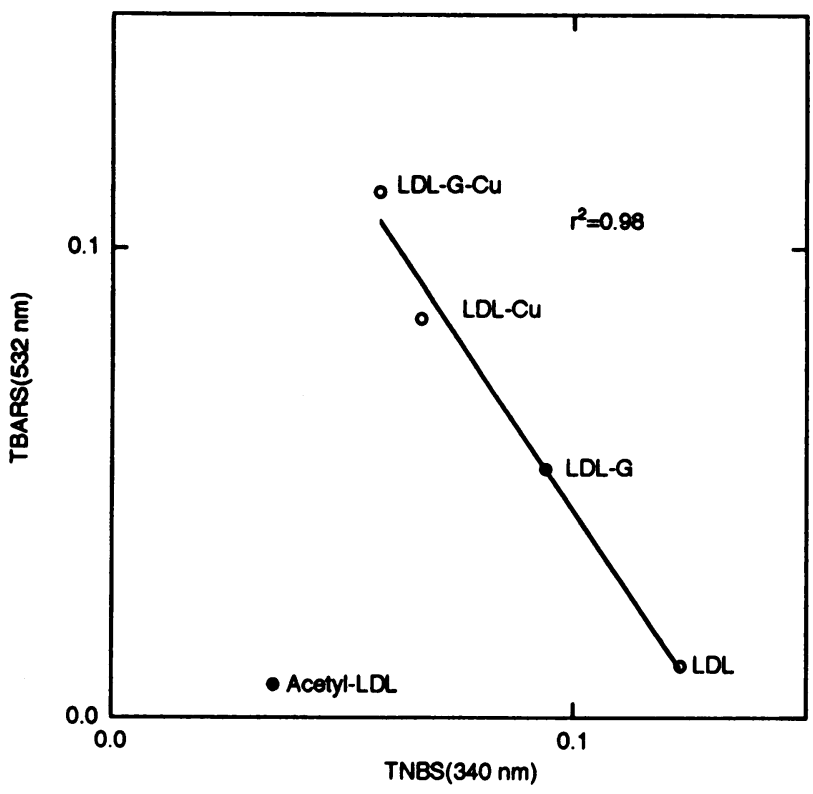

Figure 5. Relationship between oxidative modification and free amino groups on lipoproteins. LDL was incubated for $48 \mathrm{~h}$ under the conditions described in the legend to Fig. 4 in the absence of DTPA. The extent of lipid peroxidation was assessed as TBARS and free amino groups as TNBS reactivity as described in Methods. Values shown are means of duplicate determinations. The experiment was repeated three times. $L D L$, no additions; $L D L-G, 25 \mathrm{mM}$ glucose; $L D L-C u, 0.5 \mu \mathrm{M} \mathrm{CuSO}_{4}$; $L D L-G-C u, 25 \mu \mathrm{M}$ glucose, $0.5 \mu \mathrm{M} \mathrm{CuSO}_{4}$.

anion. Since catalase was not inhibitory, either the reaction does not involve hydrogen peroxide or the oxidant is generated at a sequestered site that is inaccessible to catalase. LDL oxidation was also inhibited by DTPA, a metal chelator, indicating that transition metal ions are likely to play a role. Low levels of metal ions may be endogenously bound to LDL (36) and are ubiquitously present in the buffers used for biochemical studies (34). It is noteworthy that low levels of protein-bound metal ions have been implicated in the oxidative damage of tissue during aging (37) and that products generated by metal-catalyzed glycoxidation reactions accumulate in the proteins of diabetic patients (15). Thus, protein-bound metal ions may catalyze oxidation reactions in vivo.

The pathway for LDL oxidation was apparently different when both glucose and copper were present in the reaction mixture. Under these conditions, LDL oxidation was partially inhibited by either SOD or catalase, and the enzymes together completely blocked lipid peroxidation. Thus, both superoxide and hydrogen peroxide appear to play a role in the stimulation of LDL oxidation by glucose together with copper. One potential mechanism consistent with these observations is generation of hydroxyl radicals $\left(\mathrm{HO}^{\circ}\right)$ by superoxide-driven Haber-Weiss chemistry (Eq. 1-3) (35):

$\mathrm{O}_{2}^{-}+\mathrm{M}^{\mathrm{n}} \rightarrow \mathrm{O}_{2}+\mathrm{M}^{\mathrm{n}-1}$

$\mathrm{M}^{\mathrm{n}-1}+\mathrm{H}_{2} \mathrm{O}_{2} \rightarrow \mathrm{M}^{\mathrm{n}}+\mathrm{HO}^{\bullet}+\mathrm{OH}^{-}$

Sum $\mathrm{O}_{2}^{-}+\mathrm{H}_{2} \mathrm{O}_{2} \rightarrow \mathrm{O}_{2}+\mathrm{HO}^{-}+\mathrm{OH}^{-}$

Consistent with this hypothesis, hydroxyl radicals are a potent initiator of lipid peroxidation and are known to damage both proteins and lipids by $\mathrm{H}^{*}$ abstraction. However, glucose reacts rapidly with hydroxyl radical (rate constant $1 \times 10^{9} \mathrm{M}^{-1} \cdot \mathrm{S}^{-1}$ ) (38), suggesting that initiation of lipid peroxidation by this pathway would be site specific. The recent demonstration that LDL binds copper ions (36) raises the interesting possibility that such oxidative reactions might take place at the interface between the aqueous and lipid phases of the lipoprotein. Alternatively, Aust and Minotti (39) have proposed that an optimum mixture of reduced and oxidized iron is necessary for initiation of liposomal peroxidation. According to this theory, $\mathrm{O}_{2}^{-}$and a LDL
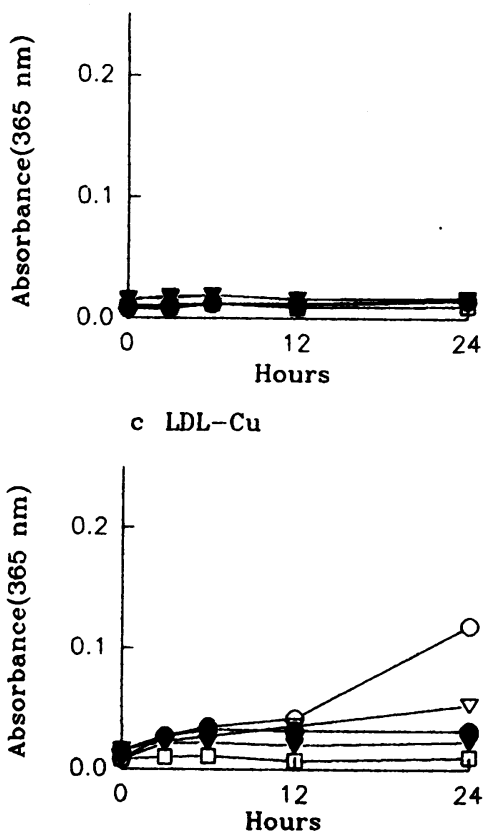

b LDL-G

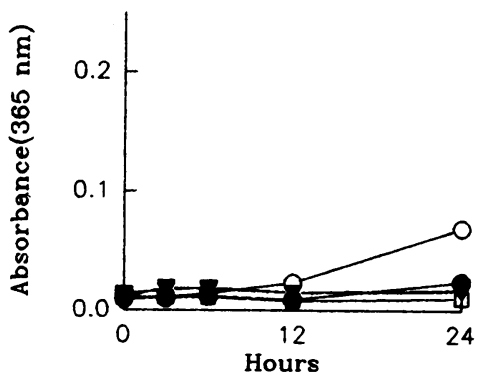

d LDL-G-Cu

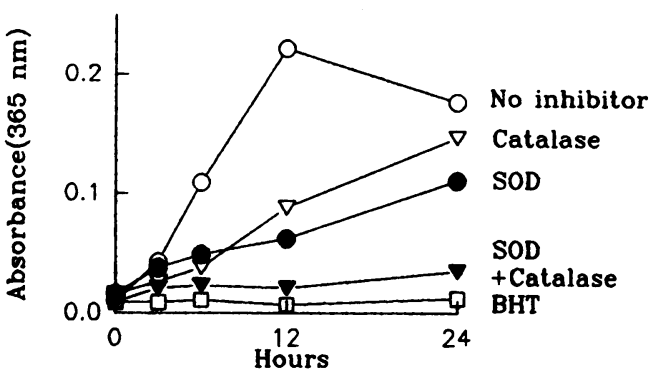

Figure 6. Effect of inhibitors of oxidation on glucose- and copper-mediated modification of LDL. LDL was incubated with no addition (Fig. $6 a$ ), with glucose ( $25 \mathrm{mM}$ ) alone (Fig. $6 b), \mathrm{CuSO}_{4}(0.5 \mu \mathrm{M})$ alone (Fig. $6 c$ ), and glucose and $\mathrm{CuSO}_{4}$ (Fig. $6 d$ ) for the indicated times in the absence of inhibitor $(O)$ or in the presence of $30 \mu \mathrm{g} / \mathrm{ml}$ SOD $(\bullet), 50$ $\mu \mathrm{g} / \mathrm{ml}$ catalase $(\nabla)$, SOD and catalase $(\nabla)$, or $25 \mu \mathrm{M}$ BHT ( $\square$ ), after which the lipid peroxide content was determined by the iodometric reaction as described in Methods. Values shown are means of duplicate determinations. The results shown are representative of three similar experiments. 
Table I. Effect of Scavengers of Reactive Oxygen Species on Glucose-stimulated LDL Oxidation

\begin{tabular}{|c|c|c|c|}
\hline & $\begin{array}{c}\text { Lipid } \\
\text { peroxides* }\end{array}$ & $\begin{array}{l}\text { TBARS }^{\ddagger} \\
\text { (percentage } \\
\text { of control) }\end{array}$ & $\begin{array}{c}\text { Conjugated } \\
\text { dienes }^{5}\end{array}$ \\
\hline Complete system & $168 \pm 3(100)$ & $50 \pm 4(100)$ & $871 \pm 7 \quad(100)$ \\
\hline \multicolumn{4}{|l|}{ Complete system minus } \\
\hline \multicolumn{4}{|l|}{ Complete system plus } \\
\hline $\mathrm{SOD}(5 \mu \mathrm{g} / \mathrm{ml})$ & $34 \pm 2(20)$ & $15 \pm 1(29)$ & $389 \pm 2 \quad(45)$ \\
\hline Heat-inactivated SOD & $172 \pm 7(102)$ & $61 \pm 3(123)$ & $843 \pm 11(97)$ \\
\hline Catalase $(5 \mu \mathrm{g} / \mathrm{ml})$ & $150 \pm 2(89)$ & $40 \pm 9(81)$ & $826 \pm 5 \quad(95)$ \\
\hline Heat-inactivated catalase & $184 \pm 3(109)$ & $52 \pm 9(104)$ & $864 \pm 7 \quad(99)$ \\
\hline SOD plus catalase & $49 \pm 3(29)$ & $20 \pm 1(40)$ & $484 \pm 10(56)$ \\
\hline
\end{tabular}

The complete system consisted of LDL ( $200 \mu \mathrm{g} / \mathrm{ml}), 15 \mathrm{mM}$ glucose, and $1 \mu \mathrm{M}$ EDTA in sodium phosphate buffer (100 mM, pH 7.4). SOD and catalase were heat-inactivated by autoclaving and boiling for 10 min, respectively. After incubation for $120 \mathrm{~h}$ at $37^{\circ} \mathrm{C}$ in $95 \%$ air $/ 5 \%$ $\mathrm{CO}_{2}$, the reaction mixture was assayed for lipid peroxides and TBARS as described in Methods. Values represent the mean \pm SD of quadruplicate determinations. The results are representative of three similar experiments. ${ }^{*} \mathrm{~A}_{365} \times 1,000 ;{ }^{\ddagger} \mathrm{A}_{532} \times 1,000 ;{ }^{8} \mathrm{~A}_{234} \times 1,000$ after a $1: 5$ dilution of the sample.

$\mathrm{H}_{2} \mathrm{O}_{2}$ modulate lipid peroxidation by altering the amounts of $\mathrm{Fe}^{3+}$ and $\mathrm{Fe}^{2+}: \mathrm{O}_{2}^{-}$would reduce $\mathrm{Fe}^{3+}$ to $\mathrm{Fe}^{2+}$ while $\mathrm{H}_{2} \mathrm{O}_{2}$ would oxidize $\mathrm{Fe}^{2+}$ to $\mathrm{Fe}^{3+}$. At an optimal ratio of reduced to oxidized metal ion, lipid peroxidation is initiated. Scavengers of $\mathrm{O}_{2}^{-}$and $\mathrm{H}_{2} \mathrm{O}_{2}$ would affect the ratio and thereby inhibit lipid peroxidation. Similar reactions might be involved with the glucose-mediated oxidation of LDL. The marked inhibition of oxidative damage by a scavenger of lipid radicals, BHT, is consistent with inhibition of the propagation phase of the lipid peroxidation that might occur during either reaction pathway. Consonant with our observations, previous studies have demonstrated the generation of oxidants like superoxide, hydrogen peroxide, and hydroxyl radicals during nonenzymatic glycation of proteins $(16,17,40)$ as well as by monosaccharide autoxidation (14$17,40-42)$.
Derivatization of lysine $\epsilon$-amine residue on apolipoprotein B100 alters the receptor recognition of LDL and thereby controls its uptake and degradation by cells $(33,43)$. When lysine residues are modified by acetylation or by reaction with malondialdehyde, LDL becomes a ligand for the scavenger receptor on macrophages but loses recognition by the LDL receptor on human fibroblasts $(33,43)$. Derivatization of lysine amines by reactive aldehydes generated during lipid peroxidation may likewise be important in mediating the binding of oxidatively modified LDL to the scavenger receptor (44). Similar reactions might cause LDL modified in the presence of glucose to gain scavenger receptor recognition. Alternatively, nonenzymatic protein glycation may alter cell-surface recognition of the modified lipoprotein (2-4). To investigate the relative contributions of these pathways to alterations in apolipoprotein B-100 of modified LDL in the presence of glucose, we monitored the reactivity of protein amino groups with TNBS. This reagent predominantly reacts with free amines on lysines that are accessible to the aqueous phase (28). When LDL was incubated with glucose and copper, over $50 \%$ of TNBS reactivity was lost. The decrease in reactive amino groups was associated with an increase in lipid peroxidation products as measured by TBARS. Inclusion of DTPA, which chelates the metal ions necessary for propagation of lipid peroxidation in a redox inactive form (9), blocked both loss of TNBS reactivity and formation of TBARS. Although the slow process of nonenzymatic protein glycation can be inhibited slightly by metal ion chelation (45), we observed complete inhibition both of loss of TNBS reactivity and of increase in lipid peroxidation in the presence of DTPA. This observation strongly suggests that loss of free amino groups is likely to reflect oxidative damage to apolipoprotein B-100 by a glucose-dependent mechanism. However, we cannot exclude the possibility that nonenzymatic glycation of LDL, below the level of detection of the TNBS assay, contributed to the oxidative modification by generating reactive oxygen species.

The cellular metabolism of glucose-modified LDL was examined using cultured human skin fibroblasts and human monocyte-derived macrophages. Uptake of the modified LDL by fibroblasts decreased with increasing oxidative modification. The uptake and degradation of LDL oxidized in the presence of both glucose and copper by fibroblasts were considerably inhibited relative to unmodified LDL, consistent with decreased recogni- a Macrophages

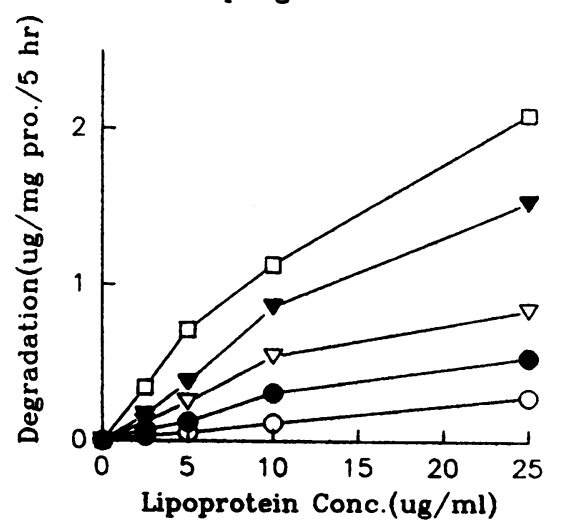

b Fibroblasts

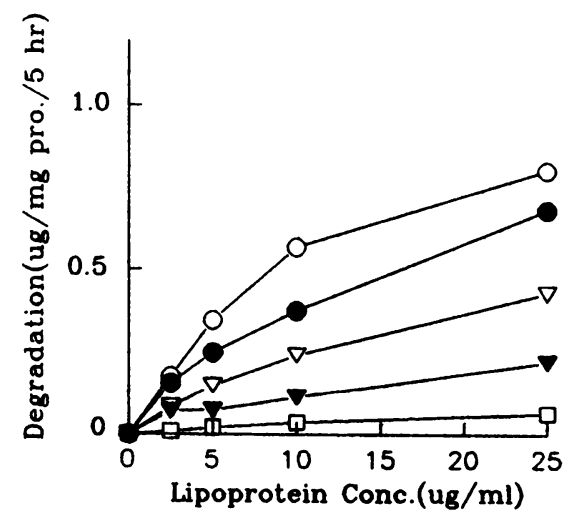

Figure 7. Degradation of modified lipoproteins by cultured human monocyte-derived macrophages (Fig. $7 a$ ) and human skin fibroblasts (Fig. 7 b $).{ }^{125} \mathrm{I}$-labeled LDL $(200 \mu \mathrm{g} / \mathrm{ml})$ was modified by incubation in the absence $(0)$, or presence of glucose $(25 \mathrm{mM})$ alone $(\bullet)$, $\mathrm{CuSO}_{4}(0.5 \mu \mathrm{M})$ alone $(\nabla)$, or glucose and $\mathrm{CuSO}_{4}$ together $(\nabla)$ for $48 \mathrm{~h}$ as described in the legend to Fig. 1. After dialysis versus 150 $\mathrm{mM} \mathrm{NaCl}, 50 \mu \mathrm{M}$ DTPA at $4^{\circ} \mathrm{C}$ under $\mathrm{N}_{2}$ to remove glucose and copper, the modified lipoproteins or acetylated LDL $(\square)$ were incubated with cultured macrophages (Fig. $7 a$ ) or skin fibroblasts (Fig. $7 b$ ) at the final concentrations indicated. After $5 \mathrm{~h}$ of incubation at $37^{\circ} \mathrm{C}$, aliquots of medium were removed for assay of lipoprotein degradation as described in Methods. Values shown are means of triplicate determinations. The results are representative of two similar experiments. 
a Macrophages

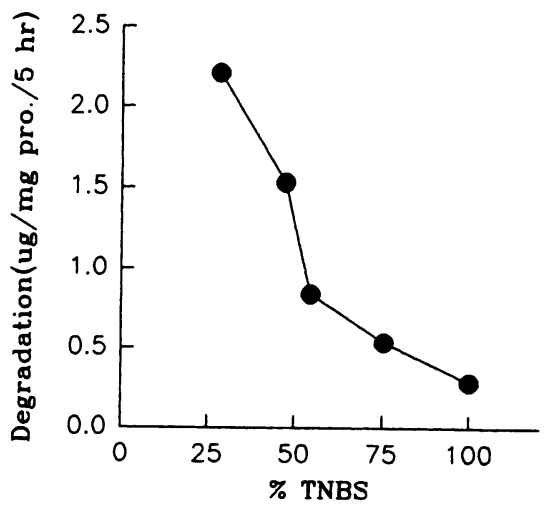

b Fibroblasts

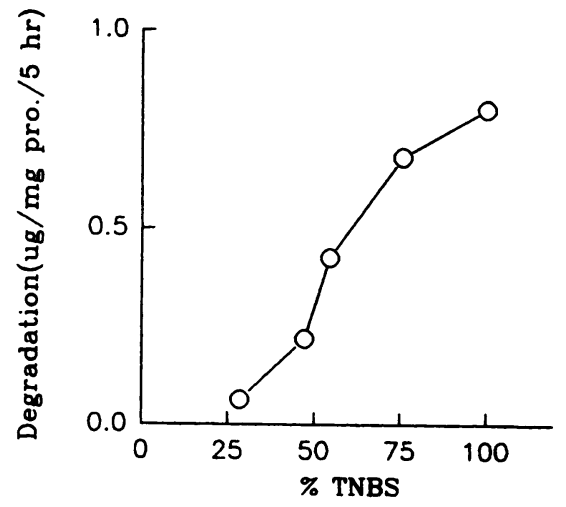

Figure 8. Relationship between free amino groups on LDL and degradation by cultured cells. Protein amino groups in unmodified and various modified forms of ${ }^{125} \mathrm{I}$-labeled LDL (Fig. 7), determined by measurement of TNBS reactivity, were related to the degradation of these lipoproteins by cultured macrophages (Fig. $8 a$ ) and skin fibroblasts (Fig. $8 b$ ). Values shown are means of triplicate determinations. tion of the modified lipoprotein by the LDL receptor $(33,43$, 46 ). Degradation by fibroblasts of LDL modified in the presence of glucose or copper alone was inversely proportional to the extent of modification as assessed by TBARS and TNBS reactivity. In contrast, the uptake of the modified LDL by human monocyte-derived macrophages was enhanced with increasing oxidative modification. The extent of degradation by both fibroblasts and macrophages was related to the degree of lysine derivatization of apolipoprotein B-100. As the number of lysines reactive with TNBS decreased in macrophages, uptake and degradation increased, while fibroblasts internalized and degraded the modified lipoprotein less efficiently. These findings are consistent with uptake of the modified LDL by the macrophage scavenger receptor(s) (33) and suggest that modification of LDL induced by chronic hyperglycemia might be an important contributing factor in accelerating foam cell formation in diabetes.

Oxidized LDL has been shown to affect multiple events that might be involved in atherogenesis (11), including monocyte chemotaxis (7), cytotoxicity (47), cytokine and growth factor production $(48,49)$, endothelium-derived relaxing factor-mediated vascular reactivity $(50)$, and foam cell formation $(7,9$, $26,34)$. If chronic hyperglycemia facilitates these events by promoting lipoprotein oxidation, this may explain in part the vascular disease observed in diabetes. Further studies are required to firmly establish whether lipoprotein oxidation is increased in patients suffering from diabetes, since these processes might be amenable to antioxidant therapy. Such antioxidants may prove to be important in preventing the markedly increased incidence of atherosclerotic complications in this common and debilitating disease.

\section{Acknowledgments}

The authors thank Charlotte Campbell, Shari Wang, and Tom Johnson for excellent technical assistance, and Julie Kirk and Pat Burns for typing the manuscript.

This research was supported in part by grants from the National Institutes of Health (DK-02456 and R01 HD-29920).

\section{References}

1. Kannel, W. B., and D. L. McGee. 1979. Diabetes and cardiovascular risk factors: the Framingham study. Circulation. 59:8-13.

2. Lopes-Virella, M. F., R. L. Klein, T. J. Lyons, H. C. Stevenson, and J. L.
Witztum. 1988. Glycosylation of LDL enhances cholesteryl ester synthesis in human monocyte-derived macrophages. Diabetes. 37:550-557.

3. Schleicher, E., B. Olgemoller, J. Schon, T. Durst, and O. H. Wieland. 1985. Limited nonenzymatic glycosylation of low-density. lipoprotein does not alter its catabolism in tissue culture. Biochim. Biophys. Acta. 846:226-233.

4. Witztum, J. L., and T. Koschinsky. 1989. Metabolic and immunological consequences of glycation of low density lipoproteins. Prog. Clin. Biol. Res. 304:219-234.

5. Lopes-Virella, M. F., R. L. Griffith, K. A. Shunk, and G. T. Virella. 1991. Enhanced uptake and impaired intracellular metabolism of low density lipoproteins complexed with anti-low density lipoprotein antibodies. Arterioscler. Thromb. 11:1356-1367.

6. Lyons, T. J. 1991. Oxidized low density lipoproteins: a role in the pathogenesis of atherosclerosis in diabetes. Diabetic Med. 8:411-419.

7. Steinberg, D., S. Parthasarathy, T. E. Carew, J. C. Khoo, and J. L. Witztum. 1989. Beyond cholesterol: modifications of LDL that increase its atherogenicity. N. Engl. J. Med. 320:916-924.

8. McNally, A. K., G. M. Chisolm, D. W. Morel, and M. K. Cathcart. 1990. Activated human monocytes oxidize low density lipoprotein by a lipoxygenasedependent pathway. J. Immunol. 145:254-259.

9. Heinecke, J. W., L. Baker, H. Rosen, and A. Chait. 1986. Superoxidemediated modification of low density lipoprotein by arterial smooth muscle cells. J. Clin. Invest. 77:757-761.

10. Hiramatsu, K., H. Rosen, J. W. Heinecke, G. Wolfbauer, and A. Chait. 1986. Superoxide initiates oxidation of low density lipoproteins by human monocytes. Arteriosclerosis. 7:55-60.

11. Rosenfeld, M. E. 1991. Oxidized LDL affects multiple atherogenic cellular responses. Circulation. 83:2138-2140.

12. Nishigaki, I., M. Hagihara, H. Tsunekawa, M. Maseki, and K. Yagi. 1981. Lipid peroxide levels of serum lipoprotein fractions of diabetic patients. Biochem. Med. 25:373-378.

13. Morel, D. W., and G. M. Chisolm. 1989. Antioxidant treatment of diabetic rats inhibits lipoprotein oxidation and cytotoxicity. J. Lipid Res. 30:1827-1834.

14. Thornalley, P. J. 1985. Monosaccharide auto-oxidation in health and disease. Environ. Health Perspect. 64:297-307.

15. Baynes, J. W. 1991. Role of oxidative stress in development of complications in diabetes. Diabetes. 40:405-412.

16. Gillery, P., J. C. Monboisse, F. X. Maquart, and J. P. Borel. 1988. Glycation of proteins as a source of $\mathrm{O}_{2}^{-}$. Diabetes Metab. Rev. 14:25-30.

17. Hunt, J. V., C. C. Smith, and S. P. Wolff. 1990. Autoxidative glycosylation and possible involvement of peroxides and free radicals in LDL modification by glucose. Diabetes. 39:1420-1424.

18. Chung, B. H., T. Wilkinson, J. C. Geer, and J. P. Segrest. 1980. Preparative and quantitative isolation of plasma lipoproteins: rapid, single discontinuous density gradient ultracentrifugation in a vertical rotor. J. Lipid Res. 21:284-291.

19. Gutteridge, J. M. C., and B. Halliwell. 1990. The measurement and mechanism of lipid peroxidation in biological systems. Trends Biochem. Sci. 15:129135

20. Esterbauer, H., G. Striegl, H. Duhl, and M. Rotheneder. 1989. Continuous monitoring of in vitro oxidation of human low density lipoprotein. Free Radical Res. Commun. 6:67-75.

21. El-Saadani, M., H. Esterbauer, M. El-Sayed, M. Goher, A. Y. Nassar, and G. Jurgens. 1989. A spectrophotometric assay for lipid peroxides in serum lipoprotein using a commercially available reagent. J. Lipid Res. 30:627-630.

22. Buege, J. A., and S. D. Aust. 1978. Microsomal lipid peroxidation. Methods Enzymol. 52:302-310.

23. Basu, S. K., J. L. Goldstein, R. G. W. Anderson, and M. S. Brown. 1976. 
Degradation of cationized low density lipoproteins and regulation of cholesterol metabolism in homozygous familial hypercholesterolemia fibroblasts. Proc. Natl. Acad. Sci. USA. 73:3178-3182.

24. Bilheimer, D. W., S. Eisenberg, and R. I. Levy. 1972. The metabolism of very low density lipoprotein proteins. Biochim. Biophys. Acta. 260:212-221.

25. Böyum, A. 1968. Isolation of mononuclear cells and granulocytes from human blood. Scand. J. Clin. Lab. Invest. 21(Suppl.):77-99.

26. Heinecke, J. W., H. Rosen, L. A. Suzuki, and A. Chait. 1987. The role of sulfur-containing amino acids in superoxide production and modification of low density lipoprotein by arterial smooth muscle cells. J. Biol. Chem. 262:10098-10103.

27. Lowry, O. H., N. J. Rosebrough, A. L. Farr, and R. J. Randall. 1951 Protein measurement with the Folin phenol reagent. J. Biol. Chem. 193:265-275.

28. Habeeb, A. F. S. A. 1966. Determination of free amino groups in proteins by trinitrobenzenesulfonic acid. Anal. Biochem. 14:328-336.

29. Flohe, L., and F. Otting. 1984. Superoxide dismutase assays. Methods Enzymol. 105:93-104.

30. Catalase. In Worthington Enzyme Manual. 1972. Worthington Biochem Corp., Freehold, NJ. 41-42.

31. Thomas, C. E. 1992. The influence of medium components on $\mathrm{Cu}^{2+}$ dependent oxidation of low density lipoproteins and its sensitivity to superoxide dismutase. Biochim. Biophys. Acta. 1128:50-57.

32. Jessup, W., J. A. Simpson, and R. T. Dean. 1993. Does superoxide radical have a role in macrophage-mediated oxidative modification of LDL? Atheroscle rosis. 99:107-120.

33. Brown, M. S., and J. L. Goldstein. 1983. Lipoprotein metabolism in the macrophage: implications for cholesterol deposition in atherosclerosis. Annu. Rev. Biochem. 52:223-261.

34. Heinecke, J. W., H. Rosen, and A. Chait. 1984. Iron and copper promote modification of low density lipoprotein by human arterial smooth muscle cells in culture. J. Clin. Invest. 74:1890-1894.

35. Halliwell, B., and J. M. C. Gutteridge. 1989. Role of free radicals and catalytic metal ions in human disease: an overview. Methods Enzymol. 186:183.

36. Kuzuya, M., K. Yamada, T. Hayashi, C. Funaki, M. Naito, K. Asai, and F. Kuzuya. 1992. Role of lipoprotein-copper complex in copper catalyzedperoxidation of low-density lipoprotein. Biochim. Biophys. Acta. 1123: $334-341$.
37. Stadtman, E. R. 1992. Protein oxidation and aging. Science (Wash. DC). 257:1220-1224.

38. Anbar, M., and P. Neta. 1967. A compilation of specific bimolecular rate constants for the reactions of hydrated electrons, hydrogen atoms, and hydroxyl radicals with inorganic and organic compounds in aqueous solution. Int. J. Appl. Radiat. Isot. 18:493-523.

39. Minotti, G., and S. D. Aust. 1992. Redox cycling of iron and lipid peroxidation. Lipids. 27:219-226.

40. Azevado, M. S., J. Raposa, J. Falcao, G. Fontes, and C. Manso. 1988. O2-radical generation by Maillard compounds. J. Diabetic Complications. 2:1921.

41. Hunt, J. V., R. T. Dean, and S. P. Wolff. 1988. Hydroxyl radical production and autoxidative glycosylation. Biochem. J. 256:205-212.

42. Thornalley, P. J., and A. Stern. 1984. The production of free radicals during the autoxidation of monosaccharides by buffer ions. Carbohydr. Res. 134:191-204.

43. Haberland, M. E., C. L. Olch, and A. M. Folgelman. 1984. Role of lysines in mediating interaction of modified low density lipoproteins with the scavenger receptor of human monocyte macrophages. J. Biol. Chem. 259:11305-11311.

44. Steinbrecher, U. P., M. Lougheed, W.-C. Kwan, and M. Dirks. 1989. Recognition of oxidized low density lipoprotein by the scavenger receptor of macrophages results from derivatization of apolipoprotein B by products of fatty acid peroxidation. J. Biol. Chem. 264:15216-15223.

45. Wolff, S. P., and R. T. Dean. 1987. Glucose autoxidation and protein modification. Biochem. J. 245:243-250.

46. Brown, M. S., and J. L. Goldstein. 1986. A receptor-mediated pathway for cholesterol homeostasis. Science (Wash. DC). 232:34-47.

47. Kosugi, K., D. W. Morel, P. E. DiCorletto, and G. M. Chisolm. 1987. Toxicity of oxidized LDL to cultured fibroblasts is selective for $\mathrm{S}$ phase of the cell cycle. J. Cell. Physiol. 130:311-320.

48. Malden, L. T., A. Chait, E. W. Raines, and R. Ross. 1991. The influence of oxidatively modified lipoproteins on expression of platelet-derived growth factor by human monocyte-derived macrophages. J. Biol. Chem. 25:1390113907.

49. Hamilton, T. A., G. P. Ma, and G. M. Chisolm. 1990. Oxidized low density lipoprotein suppresses the expression of tumor necrosis factor-alpha mRNA in stimulated murine peritoneal macrophages. J. Immunol. 144:2343-2350.

50. Galle, J., A. Mülsch, R. Busse, and E. Bassenge. 1991. Effects of native and oxidized low density lipoproteins on formation and inactivation of endotheliumderived relaxing factor. Arterioscler. Thromb. 11:198-203. 